\title{
Energy Level in Large Intestinal Mucosa in Patients with Ulcerative Colitis
}

\author{
Jin-Ichi Kameyama, Hideo Narui, Masaru Inui and \\ Toshio Sato \\ Department of Surgery, Tohoku University School of \\ Medicine, Sendai 980
}

\begin{abstract}
Kameyama, J., Narui, H., Inui, M. and Sato, T. Energy Level in Large Intestinal Mucosa in Patients with Ulcerative Colitis. Tohoku J. exp. Med., 1984, 143(2), 253-254 In 7 patients with ulcerative colitis, the energy level in the large intestinal mucosa was investigated. ATP and energy charge in the intestinal mucosa in ulcerative colitis showed lower levels than those of control subjects. Therefore, energy-deficit may exist in the large intestinal mucosa in ulcerative colitis. ulcerative colitis ; energy level ; ATP ; energy charge
\end{abstract}

Energy-deficit in the gastric mucosa is considered one of the factors in the pathogenesis of acute gastric mucosal lesions (Menguy et al. 1974; Kameyama et al. 1982). The pathogenesis of acute gastric mucosal lesions and ulcerative colitis may be different. However, we decided to investigate further and have therefore studied the energy level in the large intestinal mucosa in ulcerative colitis, which has not yet been reported.

Patients and materials. Seven patients with ulcerative colitis (5 males and 2 females, mean age of 34 years) and 7 control subjects ( 5 males and 2 females, mean age of 58 years) were studied. Of the 7 patients with ulcerative colitis, 6 were in the active stage, severe colitis and total colitis, and one was in the healed stage, mild colitis and left side colitis. Control subjects included 4 with sigmoid colon cancer, 2 with rectal cancer and one with transverse colon cancer without intestinal stenosis. The large intestine was crushed between two copper paddles precooled to the temperature of liquid $\mathrm{N}_{2}$, soon after laparotomy before the intestinal circulation was disturbed. The specimens were taken from the severe and moderate lesions in ulcerative colitis. For the control, specimens of normal colon from patients with large bowel cancer, from a part of the colon that would later be resected, but as far from the tumor as possible. The harvested specimens were dealt with by the "stopfreeze" method, and ATP, ADP and AMP were determined using coupled enzyme reactions for the assays (Dennemann 1961; Jaworek et al. 1974). Energy charge proposed by Atkinson (1968) calculated from $(\mathrm{ATP}+1 / 2 \mathrm{ADP}) /(\mathrm{ATP}+\mathrm{ADP}+\mathrm{AMP})$ was also estimated. In statistical analyses, measured values were expressed as meal \pm S.D. and the significance of the differences was evaluated by using Student's $t$-test.

Results and comments. ATP levels were $1.65 \pm 0.62 \mu \mathrm{mol} / \mathrm{g} \cdot$ wet wt. in control subjects. In ulcerative colitis, the levels of the severe lesions were $1.12 \pm 0.2 \mu \mathrm{mol} / \mathrm{g} \cdot$ wet wt., significantly lower than those of control subjects $(p<0.05)$. The levels of the moderate lesions of $1.06 \pm 0.13 \mu \mathrm{mol} / \mathrm{g} \cdot$ wet wt. were also lower than those of control subjects. No significant difference was found between the severe and moderate lesions in ulcerative colitis $(p>0.05)$ (Fig. 1, left) (Table 1).

Energy charge levels were $0.84 \pm 0.03$ in control subjects. In ulcerative colitis, the levels of the severe lesions of $0.80 \pm 0.05$ were lower than those of control subjects. The levels of the moderate lesions were $0.77 \pm 0.04$, significantly lower than those of controls $(p<$ 0.05). No significant difference was found between the severe and moderate lesions in ulcerative colitis $(p>0.05)$ (Fig. 1, right) (Table 1).

These results suggest that energy-deficit may exist in the large intestinal mucosa in

Received for publication, November 15, 1983. 

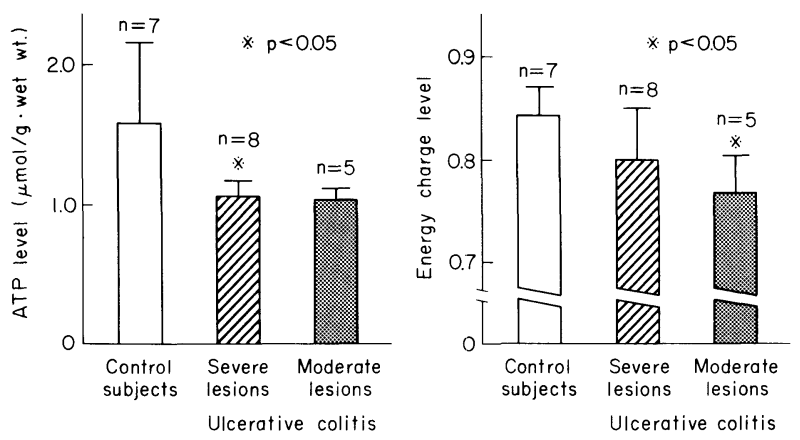

Fig. 1. ATP and energy charge levels in the large intestinal mucosa.

TABLE 1. Energy levels in the large intestinal mucosa

\begin{tabular}{|c|c|c|c|}
\hline & \multirow{2}{*}{$\begin{array}{c}\text { Control } \\
(n=7)\end{array}$} & \multicolumn{2}{|c|}{ Ulcerative colitis } \\
\hline & & $\begin{array}{l}\text { Severe lesions } \\
\quad(n=8)\end{array}$ & $\begin{array}{l}\text { Moderate lesions } \\
\qquad(n=5)\end{array}$ \\
\hline ATP* & $1.65 \pm 0.23 \dagger$ & $1.12 \pm 0.07 \dagger$ & $1.06 \pm 0.06$ \\
\hline $\mathrm{ADP}^{*}$ & $0.57 \pm 0.09$ & $0.47 \pm 0.08$ & $0.54 \pm 0.07$ \\
\hline $\mathrm{AMP}^{*}$ & $0.08 \pm 0.01 \dagger$ & $0.11 \pm 0.01$ & $0.14 \pm 0.02 \dagger$ \\
\hline $\mathrm{ATP}+\mathrm{ADP}+\mathrm{AMP}^{*}$ & $2.30 \pm 0.31$ & $1.71 \pm 0.12$ & $1.74 \pm 0.11$ \\
\hline Energy charge & $0.84 \pm 0.01 \dagger$ & $0.80 \pm 0.02$ & $0.77 \pm 0.02 \dagger$ \\
\hline
\end{tabular}

mean \pm s.E. ${ }^{*} \mu \mathrm{mol} / \mathrm{g} \cdot$ wet wt. $\quad \dagger p<0.05$.

ulcerative colitis whether the lesions are severe or moderate.

\section{References}

1) Atkinson, D.E. (1968). The energy charge of the adenylate pool as a regulatory parameter. - Interaction with feed back modifiers. Biochemistry, 7, 4030-4034.

2) Dennemann, H. (1961). Enzymatische Bestimmung von Adenosinetriphosphat im Vollblut. Z. ges. exp. Med., 134, 335-340.

3) Jaworek, D., Gruber, W. \& Bergmeyer, H.U. (1974). Adenosine-5'-diphosphate and adenosine-5'-monophosphate. In: Methods of Enzymatic Analysis, edited by H.U. Bergmeyer, Verlag Chemie Weinheim Academic Press, Inc. New York and London, pp. 2127-2129.

4) Kameyama, J., Sasaki, I., Hidenobu, M. \& Inui, M. (1982). Acute gastric mucosal lesions - Experimental and clinical studies on acute gastroduodenal ulcer in obstructive jaundice. Jap. J. Gastroent. Surg., 16, 1641-1645. (Japanese)

5) Menguy, R., Desbaillets, L. \& Masters, Y.F. (1974). Mechanism of stress ulcer : Influence of hypovolemic shock on energy metabolism in the gastric mucosa. Gastroenterology, 66, 46-55. 